\title{
Health related quality of life among the people living with HIV
}

\author{
Imam $\mathrm{MH}^{1}$, Karim $\mathrm{MR}^{1}$, Ferdous $\mathrm{C}^{2}$, Akhter $\mathrm{S}^{3}$ \\ ${ }^{1}$ Department of Epidemiology, National Institute of Preventive \& Social Medicine, Dhaka, ${ }^{2}$ Bangladesh Institute \\ of Health Science, Dhaka, ${ }^{3}$ Combined Military Hospital, Dhaka Cantonment, Dhaka.
}

\begin{abstract}
Identifying the level of health related quality of life (HQoL) and their influencing factors in human immunodeficiency virus (HIV) positive people is of extreme importance in implementing an interventional program to support this group. This cross sectional study was an attempt to determine the level and factors associated with HQoL among the people living with HIV. A convenient sample of 82 HIV-infected people from three NGOs and one Infectious Disease Hospital (IDH), were interviewed using an interviewer administered, semi structured questionnaire developed by adopting the "WHOQOL-HIV BREF instrument". A majority of the respondents were with low Quality of Life (QoL) in all the domains of HQoL. The proportion of respondents with low QoL was highest in the domain of social relationship (64.6\%) followed by psychological domain $(59.8 \%)$, physical domain $(58.5 \%)$, level of independence domain $(56.1 \%)$, environmental domain $(52.4 \%)$ and spirituality domain $(52.4 \%)$ of HQoL. Bivariate analysis revealed that the overall perception of QoL was better in the respondents living in urban area, who were employed and asymptomatic of the centre for disease control (CDC) stage of HIV. The perception of overall health was higher in females, all respondents less than 35 years of age, asymptomatic of the CDC stage of disease and with a current $\mathrm{CD}_{4}$ count greater than $200 \mathrm{cell} / \mathrm{mm}^{3}$. These findings highlight the need for enhanced socio-psychosocial support and a better environment for improving the health related quality of life among people living with HIV.
\end{abstract}

\section{Introduction}

Epidemic strikes by HIV/AIDS at the root of every aspect of the society involving individuals, families, sectors and institutions ${ }^{1}$. It has ruined the social framework of many communities and countries especially in the heavily affected countries. It continues to spread and affect the lives of millions of people. The estimated global number of people living with HIV (PLHIV) including adults and children at the end of the 2009 was 33.3 million $^{2}$. The majority of them are in Sub-Saharan Africa which is estimated 22.5 million, but epidemic are emerging in Asia and Eastern Europe $^{2}$. Worldwide the number of new HIV infections was 2.6 million and the number of death due to AIDS related illness was 1.8 million during the year of $2009^{2}$. It has already become the leading cause of death in non-industrialized regions especially in Sub-Saharan Africa ${ }^{3}$.

This increasing pandemic of HIV/AIDS at present is a major global concern and a significant development issue ${ }^{3}$. However, the recent advance in knowledge about the disease, better diagnostic methods, new treatments and strengthened HIV programs have provided great hope for HIV positive people to live a long life ${ }^{4}$. For this reason the Health related Quality of Life (HQoL) of this large number of people becomes a great concern. Unfortunately there is still relatively little empirical research in understanding the health related quality of life in PLHIV in developing countries. Most of the studies have been conducted in developed and non Asian countries ${ }^{4-7}$. Findings of these studies may not be always relevant to Asian developing countries. So this current study was spcefically aimed at determining the level and associated factors of HQoL among the PLHIV in Bangladesh.

There is no single, generally accepted definition of Quality of Life (QoL). However, the current concept of quality of life in public health and medicine refers to how the individual's wellbeing including all physical, psychological, social, spiritual and environmental aspects of the individual's life may be impacted over time by a disease, a disability, or a disorder ${ }^{8}$. The World Health Organization (WHO) has defined quality of life "as an individual's perception of their position in life in the context of the culture and value systems in which they live and in relation to their goals, expectations, standards and concerns", 
A number of studies centered on the health-related quality of life of HIV-positive individuals using different types of QoL measuring tools have reported various associations between HQoL and other factors. HIV infection mainly affect on six major domains of HQoL, referred to as physical, psychological, level of independence, social, environmental and spiritual which is varied in term of Socio-demographic characteristics and disease related variables ${ }^{10}$. Socio-demographic characteristics, such as age, gender, education, income employment status and disease related variables such as disease stage, opportunistic infection, $\mathrm{CD}_{4}$ count etc have been found to be strongly associated with the QoL of PLHIV ${ }^{10}$.

\section{Methods}

\section{Setting and Sample}

This cross-sectional study was conducted on a convenient sample of $82 \mathrm{HIV}$-infected people attending for receiving services and care from three selected NGOs and one hospital during the period of January 2009 to June 2009. Although the study participants came from different districts of Bangladesh, we recruited them when they were receiving services from infectious diseases hospital (IDH), Confidential Approach to AIDS Prevention (CAAP) \& Mukto Akash Bangladesh in Dhaka and from Ashar Alo Society in Sylhet. They came to these centers for routine clinical care visit, to get treatment for other health problems and to meet to the get-together at member's day of month. As there is much scarcity of people who have tested positive \& are living with HIV/AIDS, and related difficulties in accessing them, the selection of study subjects could not be so rigid. The participants were selected on the basis of few inclusion and exclusion criteria. The inclusion criteria were included being registered with selected NGOs as HIV positive, being above 18 years of age and whose who were willingly participating in this study. The exclusion criteria were included the presence of any obvious co-morbid conditions not associated with HIV/AIDS and whose who were not willing to participate in this study.

\section{Research Instrument}

A semi-structured, pre-tested and interviewer administered questionnaire in Bangla, were used to obtain socio-demographic, disease stages and HQoL assessment. A check list was used to obtain clinical and lab information from medical records. The questionnaire was developed by adopting "31 items World Health Organization Quality of Life HIV BREF (WHOQOL-HIV BREF) instrument". It is a multidimensional, conceptualized, generic, 31-item QoL instrument ${ }^{9}$. It covers the respondent's perception of the overall quality of life within the 6 (six) broad domains: physical, psychological, level of independence, social, environmental and spiritual. There is also a general facet that measures the overall QoL and general health perceptions. The Physical domain describes 4 facets: pain and discomfort, energy and fatigue, sleep and rest and symptoms related to HIV. The Psychological domain describes 5 facets: positive feelings, concentration, self esteem, bodily image and appearance and negative feelings. The Level of independence domain describes 4 facets: mobility, activities of daily living, dependence on medication and treatment and work capacity. The Social relationships domain describes 4 facets: personal relationships, social support, sexual activity, social inclusion. The Environment domain describes 8 facets: physical safety and security, home environment, financial resources, health and social care: accessibility and quality, opportunities for acquiring new information and skills, participation in and opportunities for recreation/ leisure activities, physical environment, transport. The Spirituality, religion and personal beliefs domain describes 4 facets: personal beliefs, forgiveness and blame, concerns about the future, death and dying. Items are rated on a 5-point Likert interval scale where 1 indicates low, negative perceptions, and 5 indicates high, positive perceptions. Facet scores are the mean of the four items in each facet. Domain scores are obtained by adding the facet means in the respective domain, dividing by the number of facets in that domain, and multiplying by 4 , so that scores ranged from 4 (worst possible QoL) to 20 (best possible QoL) ${ }^{11}$. This instrument had been validated and used widely in HIV studies $^{12}$.

\section{Data Analysis}

Descriptive statistics including means, medians, standard deviations, ranges, and minimum \& maximum for continuous data and frequencies \& proportion for categorical data were calculated. For inferential statistics, mainly t-test and one way ANOVA were used for bivariate analysis. Statistical significance was set at $p \leq 0.05$. Statistical calculations were performed with the assistance of the personal-computer program SPSS 14.0 for Windows evaluation version.

\section{Ethical Implication}

Institutional Review Board (IRB) reviewed the Protocol to ensure that ethical issues were handled correctly. Informed verbal consent was taken. The respondents were informed about the objectives, purpose of the study \& other relevant information of the study. Privacy and confidentiality were 
purpose of the study \& other relevant information of the study. Privacy and confidentiality were strictly maintained. All other ethical issues were handled appropriately.

\section{Results}

Sample Characteristics

Of the total 82 participants, more than half the respondents were male $(57.3 \%)$. They were mostly $(81.7 \%)$ between $18-40$ years of age, residing in rural areas $(61.0 \%)$, were predominantly unemployed (56.1\%) and most of them (62.2\%) had no family income or less than Tk 5000 per month family income. The educational qualification of the most of the respondents was below 10 years of schooling $(51.4 \%)$ and almost one quarter of the total respondents were illiterate (24.4\%). More than half $(56.1 \%)$ of the respondents had shared their serostatus with friends. The majority of the respondents had been infected with this virus for a long time (approximately $4 \frac{1}{2}$ years). Most of them $(64.6 \%)$ were not receiving antiretroviral treatment. The respondents were almost equal in three groups of the CDC stage of HIV infection, $34.1 \%$ of respondents were in both asymptomatic and AIDS group and $31.7 \%$ were in symptomatic group. The majority of them had current CD4 counts above 200 cells $/ \mathrm{mm}^{3}$ and a history of opportunistic infections (OIs). Sample characteristics are shown in Table I.

The Mean scores of HQoL in different domains Table II shows the mean scores for the overall perception of quality of life, general health perceptions and six domains. The mean scores of Health related Quality of Life (HQoL) was highest in the domain of spirituality (13.37) followed by social relationship (12.98), physical (12.41), level of independence (12.21), environmental (11.80), and psychological (11.63) and the overall perception of quality of life and general health perceptions scores were 11.85 \& 12.54 respectively. The participants were categorized into two groups of high QoL and Low QoL using the median of the HQoL scores as cut-off point. A majority of the respondents were with low QoL in all the domains of HQoL. The proportion of respondents with low QoL was highest in the domain of social relationship (64.6\%) followed by psychological domain $(59.8 \%)$, physical domain $(58.5 \%)$, level of independence domain $(56.1 \%)$, environmental domain $(52.4 \%)$ and spirituality domain $(52.4 \%)$ of HQoL. The proportion of respondent having High or Low HQoL scores are shown in Figure 1.
Table I: Socio-demographic, Disease and treatment related characteristics of the study participants $(\mathrm{N}=82)$

\begin{tabular}{|c|c|}
\hline Variables & Frequency $(\%)$ \\
\hline \multicolumn{2}{|l|}{ Sex } \\
\hline Male & $47(57.3)$ \\
\hline Female & $35(42.7)$ \\
\hline Mean age in years $( \pm S D)$ & $34.83( \pm 7.41)$ \\
\hline \multicolumn{2}{|l|}{ Age group (years) } \\
\hline$\leq 35$ & $43(52.4)$ \\
\hline$>35$ & $39(47.6)$ \\
\hline \multicolumn{2}{|l|}{ Place of Residence } \\
\hline Urban & $30(36.6)$ \\
\hline Rural & $50(61.0)$ \\
\hline Urban Slum & $02(02.4)$ \\
\hline \multicolumn{2}{|l|}{ Occupations } \\
\hline Unemployed & $46(56.1)$ \\
\hline Employed & $36(43.9)$ \\
\hline \multicolumn{2}{|l|}{ Average monthly income in Taka } \\
\hline No Income & $19(23.2)$ \\
\hline$<=5000$ & $32(39.0)$ \\
\hline$>5000$ & $31(37.8)$ \\
\hline \multicolumn{2}{|l|}{ Education } \\
\hline Illiterate & $20(24.4)$ \\
\hline Upto 10 years of schooling & $42(51.4)$ \\
\hline College \& above & $19(23.2)$ \\
\hline \multicolumn{2}{|l|}{ Friends knowing serostatus } \\
\hline No & $34(41.5)$ \\
\hline Yes & $46(56.1)$ \\
\hline \multicolumn{2}{|l|}{ Time since diagnosis of HIV in months } \\
\hline Mean (Range) & $54.2(2-144)$ \\
\hline \multicolumn{2}{|l|}{ Antiretroviral medication } \\
\hline No & $53(64.6)$ \\
\hline Yes & $29(35.4)$ \\
\hline \multicolumn{2}{|l|}{ CDC stage of HIV infection } \\
\hline Asymptomatic & $28(34.1)$ \\
\hline Symptomatic & $26(31.7)$ \\
\hline AIDS & $28(34.1)$ \\
\hline \multicolumn{2}{|l|}{ Opportunistic infections (OIs) } \\
\hline No OIs & $17(20.7)$ \\
\hline$\geq 1$ times OIs & $65(79.3)$ \\
\hline \multicolumn{2}{|l|}{ Current CD4 count (cells $\left./ \mathrm{mm}^{3}\right)$} \\
\hline$\leq 200$ & $19(23.2)$ \\
\hline$>200$ & $63(76.8)$ \\
\hline
\end{tabular}

Table II: Mean scores for overall quality of life and general health perceptions and for six domains $(\mathrm{N}=82)$

\begin{tabular}{ll}
\hline Domains & Mean $( \pm$ SD) \\
\hline Physical & $12.41(3.03)$ \\
Psychological Domain & $11.63(2.62)$ \\
Level of Independence & $12.21(2.28)$ \\
Social Relationships & $12.98(2.41)$ \\
Environment & $11.80(1.77)$ \\
Spirituality/Religion & $13.37(3.21)$ \\
Overall perception of HQoL & $11.85(3.74)$ \\
Overall General Health Perception & $12.54(3.70)$ \\
\hline
\end{tabular}

\section{Bivariate Analyses}

We examined the association between the mean scores of HQoL and socio-demographic and disease related variables by means of the student's t-test and one-way analysis of variance (ANOVA). The result of mean scores of HQoL according to demographic, disease related characteristics are shown in Table III. The analysis revealed that the perception of overall health was higher in female, respondents with an age of less than 35 years, who were asymptomatic of the CDC stage of HIV- 
infection and whose current $\mathrm{CD}_{4}$ count was greater than 200 cell $/ \mathrm{mm}^{3}$. The overall perception of quality of life (QOL) was better in the respondents living in urban areas, who were employed and asymptomatic of the CDC stage of HIV. Younger and urban residents perceived their level of independence as better $(\mathrm{p}<0.05)$. Those subjects whose friends knew of their sero-status and who had dependent less than 4 , gave higher ratings for the social relationships domain. Subjects who were asymptomatic of the CDC stage of HIV-infection, with a current $\mathrm{CD}_{4}$ count greater than $200 \mathrm{cell} / \mathrm{mm}^{3}$ had a significantly greater mean score of HQoL in the physical and the level of independence domains. The mean scores of HQoL in the domain of environmental and spirituality was not significantly different in term of socio-demographic and disease related factors.

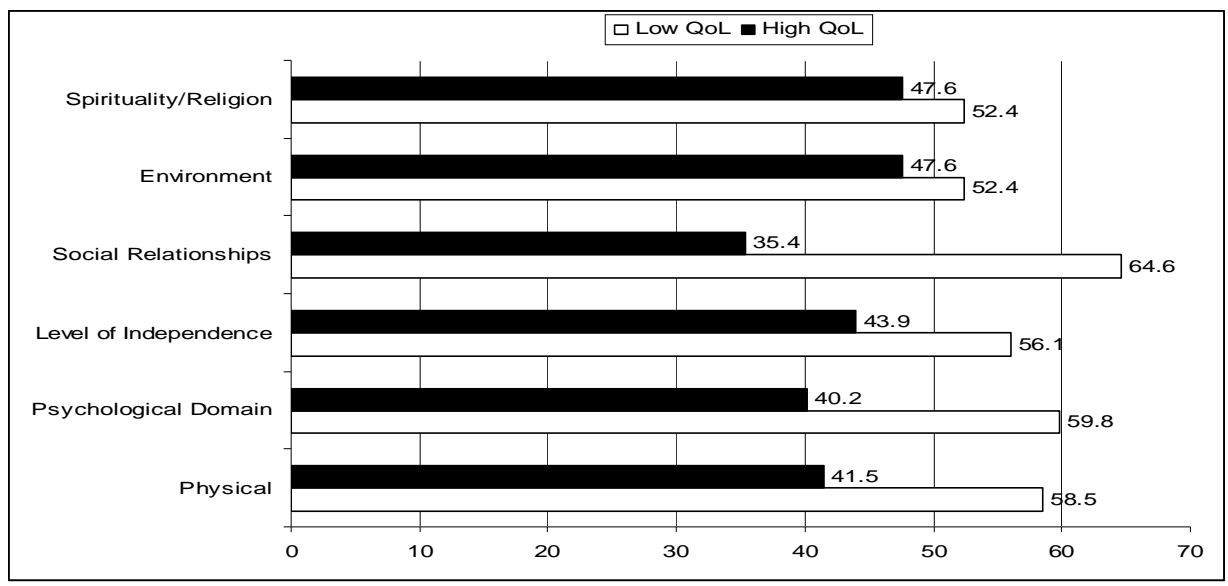

Figure 1: The proportion of respondent having High or Low HQoL scores $(\mathrm{N}=82)$

Table III The mean scores of HQoL in different domain according to demographic, disease related characteristics ( $\mathrm{N}=82$ )

\begin{tabular}{|c|c|c|c|c|c|c|c|c|c|}
\hline \multicolumn{2}{|c|}{ Variables } & Physical & Psychological & $\begin{array}{c}\text { Level of } \\
\text { Independence }\end{array}$ & $\begin{array}{c}\text { Social } \\
\text { relationship }\end{array}$ & Environmental & Spiritual & $\begin{array}{c}\text { Perception } \\
\text { of QOL }\end{array}$ & $\begin{array}{l}\text { Perception of } \\
\text { overall health }\end{array}$ \\
\hline \multirow[t]{3}{*}{ Sex } & Male & 12.15 & 11.46 & 11.79 & 13.06 & 11.69 & 13.87 & 11.74 & 11.74 \\
\hline & Female & 12.77 & 11.86 & 12.77 & 12.86 & 11.96 & 12.69 & 12.00 & 13.60 \\
\hline & T-test & -.918 & -.695 & -1.971 & .382 & -.639 & 1.676 & -.304 & 2.301-* \\
\hline \multirow[t]{3}{*}{ Age } & $\leq 35$ & 12.65 & 12.11 & 12.81 & 13.06 & 11.93 & 13.06 & 11.81 & 13.39 \\
\hline & $>35$ & 12.15 & 11.09 & 11.53 & 12.87 & 11.66 & 13.69 & 11.89 & 11.58 \\
\hline & T-Test & .739 & 1.776 & $2.625^{* *} *$ & .370 & .672 & -.877 & -.100 & $2.259^{*}$ \\
\hline \multirow[t]{3}{*}{ Residence } & Urban & 13.13 & 11.62 & 12.96 & 13.06 & 12.21 & 12.83 & 13.20 & 13.46 \\
\hline & Rural & 12.12 & 11.63 & 11.86 & 13.00 & 11.63 & 13.60 & 11.04 & 12.00 \\
\hline & T-Test & 1.462 & -.009 & $2.168^{*}$ & .119 & 1.447 & -1.029 & $2.553 *$ & 1.714 \\
\hline \multirow{3}{*}{$\begin{array}{l}\text { No .of } \\
\text { dependent. }\end{array}$} & $\geq 4$ & 12.62 & 11.43 & 12.57 & 12.35 & 11.64 & 12.82 & 11.82 & 12.97 \\
\hline & $<4$ & 12.16 & 11.87 & 11.75 & 13.72 & 12.00 & 14.02 & 11.89 & 12.00 \\
\hline & T-Test & -1.027 & .357 & -1.689 & $2.107^{*}$ & -.712 & 1.951 & -1.017 & -1.075 \\
\hline \multirow[t]{3}{*}{ Employment } & No emp. & 12.02 & 11.54 & 11.84 & 13.00 & 11.55 & 12.95 & 10.86 & 12.17 \\
\hline & employed & 12.91 & 11.73 & 12.66 & 12.94 & 12.12 & 13.88 & 13.11 & 13.00 \\
\hline & T-Test & -1.332 & -.317 & -1.634 & .103 & -1.460 & -1.312 & $-2.804 * *$ & -1.002 \\
\hline \multirow{3}{*}{$\begin{array}{l}\text { Friends } \\
\text { knowing } \\
\text { serostatus }\end{array}$} & Yes & 12.63 & 11.65 & 12.41 & 13.47 & 12.09 & 13.39 & 12.17 & 12.95 \\
\hline & No & 12.29 & 11.64 & 11.94 & 12.2 & 11.33 & 13.26 & 11.29 & 11.88 \\
\hline & T-Test & -.492 & -.009 & -.913 & $-2.399^{*}$ & -1.936 & -.174 & -1.035 & -1.338 \\
\hline \multirow[t]{4}{*}{ CDC Stage } & Asymat. & 14.03 & 12.34 & 13.32 & 13.67 & 12.21 & 13.32 & 12.85 & 14.57 \\
\hline & Sympt. & 11.46 & 11.26 & 11.65 & 12.57 & 11.46 & 13.07 & 10.30 & 11.07 \\
\hline & AIDS & 11.67 & 11.25 & 11.60 & 12.64 & 11.73 & 13.67 & 12.28 & 11.85 \\
\hline & F-Test & $7.006^{* *}$ & 1.605 & $5.689 * *$ & 1.854 & 1.286 & .237 & $3.634 *$ & $7.842 * *$ \\
\hline \multirow[t]{4}{*}{ OIs } & No OIs & 13.47 & 12.23 & 12.88 & 14.29 & 12.50 & 13.35 & 12.47 & 14.11 \\
\hline & 1 times & 14.00 & 13.12 & 13.40 & 14.40 & 11.90 & 13.60 & 12.80 & 14.40 \\
\hline & $>1$ times & 11.98 & 11.33 & 11.91 & 12.48 & 11.60 & 13.35 & 11.60 & 11.93 \\
\hline & F-Test & 2.398 & 1.679 & 1.970 & $5.154^{* *}$ & 1.755 & .014 & .523 & $3.131 *$ \\
\hline \multirow[t]{3}{*}{ CD4 Count } & $\leq 200$ & 10.89 & 10.27 & 11.05 & 12.73 & 11.34 & 13.15 & 11.78 & 10.94 \\
\hline & $>200$ & 12.87 & 12.03 & 12.55 & 13.04 & 11.94 & 13.42 & 11.87 & 13.01 \\
\hline & T-Test & $2.576^{*}$ & $2.672 * *$ & $2.612 *$ & .491 & 1.307 & .321 & .085 & $2.182 *$ \\
\hline \multirow{3}{*}{$\begin{array}{l}\text { Antiretroviral } \\
\text { Medication }\end{array}$} & No & 12.52 & 11.65 & 12.39 & 12.89 & 11.69 & 13.14 & 11.25 & 12.83 \\
\hline & Yes & 12.26 & 11.60 & 11.94 & 13.09 & 11.96 & 12.68 & 12.70 & 12.11 \\
\hline & T-Test & .375 & .085 & .890 & -.354 & -.648 & -.736 & -1.758 & .860 \\
\hline
\end{tabular}

$* \mathrm{p}<0.05, * * \mathrm{p}<0.01$ 


\section{Discussion}

According to this study, the largest portion of respondents were affected with this disease between 18- 40 years of age and this finding is congruent the report of UNAIDS/WHO Report on the global AIDS epidemic 2008, in 2007 off total about 33 million people of HIV positive, an estimates 30.8 million people were working age group (15-49 years of age $)^{3}$. The socio-economic and demographic pictures of the respondents in this study indicate that most of them had hailed from low socio-economic status. This finding of the current study is also consistent with several others studies of similar nature in different part of the world especially of developing countries ${ }^{4,6,14-17}$.

In this study, more than half of respondents had low QoL scores in all domains of HQoL which is an inverse picture of a Brazilian study ${ }^{4}$. The highest portion of individuals had low QoL in the social domain suggesting the severest impact of HIV extended across social aspect of HQoL. This is expected as people with HIV infection often experience social isolation, derogation, stigmatization, discrimination and marginalization $^{18}$. At the same time the mean scores of quality of life of the subjects appeared to be lower in compared to the PLHIV in some developed and Non-Asian countries such as Brazil ${ }^{4}$, Sweden $^{5}$, Estonia ${ }^{6}$, Croatia ${ }^{7}$ and Italy ${ }^{13}$. On the other hand the scores are higher than some developing countries such as India ${ }^{14,16}$ and $\operatorname{Iran}^{17}$.

In bivariate analysis, the result of our study shows that the women with HIV/AIDS had better overall general health perception than men in most aspects of life. Although contradictory results have been given in case of gender as a socio-demographic factor on the quality of life of individuals living with HIV/AIDS in good numbers of literatures, some researches have documented low performance for women in some aspects of quality of life $(\mathrm{QoL})^{17}$ while in some other studies difference according to gender was not found ${ }^{13}$ or had even shown the opposite ${ }^{19}$.

The respondents who reside in rural area had poorer HQoL in the domain of level of independence and overall perception of HQoL than the respondents of urban area. This finding may be due to availability of less support for HIV patients in rural area.

A significant relationship was found between being employed and overall perception of health related quality of life. This finding is consistent with other studies $^{5,17}$. Therefore, providing employment, financial self-sufficiency, and financial assistance for patients and making appropriate job safety for patients are the interventions causing promotion in quality of patients' life $\mathrm{e}^{17}$. A Brazilian study has found that having a source of income was associated with a better HQoL only with respect to the physical and psychological domains ${ }^{4}$. Some authors have acknowledged the fact that being employed is the main predictor of the HQoL scales for their population ${ }^{4,5}$ and it has been shown that the HIV-infected patients find it difficult to get and keep jobs ${ }^{4}$.

The friends knowing HIV status had a positive effect on health related quality of life in domain of social relationship. There is lack of literatures support regarding this finding. This finding could be interpreted as if a friend knows the HIV-status of an individual; he or she could support the patient in many aspect of social, psychological and emotional.

Asymptomatic respondents of this study enjoyed better HQoL in the domain of physical and level independence and had better perception regarding HQoL and general health than the respondents of symptomatic and AIDS converted reflecting the grievous nature of this disease which affects various aspects of patients' quality of life ${ }^{17}$. Similar result had ascertained in several other studies $^{4-7,17,20}$. The explanation of this finding is that those who are sick are burdened with physical symptoms of the disease, which in turn, impairs HQoL $^{21}$.

The effect of antiretroviral (ARV) treatment on the QoL of HIV-infected patients is not distinctly onesided. Quality of life can be altered by the immediate effects, the longer-term consequences of antiretroviral treatment and presence of other confounding factors ${ }^{6}$. Persons with advanced HIV disease and low QoL scores have demonstrated significant improvements in QoL with ARV treatment $^{22}$. Bivariate analysis in this present study revealed no association between use of ARV medication and QoL in all domains assessed.

The present study had some limitations that should be acknowledged. It was a cross-sectional study which doesn't allow drawing conclusion about the direction of relationship or causal relationship between outcome variables and independent variables. The respondents were one who was actively seeking routine medical care. Those who don't keep regular clinic or peer organization visit could not be included therefore the result of study may not generalized to all of the HIV positive people of Bangladesh. All the predictors of health related quality of life could not be included in this study due to lack of time and resources. And finally 
due to lack of valid and reliable Bangla version of Health related quality of life measuring instrument, we used English version of it which may not be appropriate for Bangladeshi socio- cultural context.

These findings highlight the need for enhanced socio-psychosocial support and better environment for improving the health related quality of life among PLHIV. It can be attained by offering comprehensive and integrated services to the PLHIV including primary medical care, substance abuse treatment, financial assistance, housing, food, child care and social sensitization. Finally it should be recommended to attempt further studies in longitudinal design with considering all possible predictors of HQoL in PLHIV.

\section{References}

1. Steinberg M, Johnson S, Schierhout G,Ndegwa D. 'Hitting Home: How Households Cope with the Impact of the HIV/AIDS Epidemic-A Survey of Households Affected by HIV/AIDS in South Africa. USA: The Henry J. Kaiser Family Foundation; 2002 October. 42p.Report No.6059.

2. Joint United Nations Programme on HIV/AIDS (UNAIDS). Global report: UNAIDS report on the global AIDS epidemic 2010. Geneva: Joint United Nations Programme on HIV/AIDS (UNAIDS); 2010

3. Joint United Nations Programme on HIV/AIDS (UNAIDS). Report on Global HIV/AIDS Epidemic 2008. Geneva: Joint United Nations Programme on HIV/AIDS (UNAIDS) ;2008 August

4. Razera F, Ferreira J, Bonamigo RR. Factors associated with health-related quality-of-life in HIV-infected Brazilians. International Journal of STD \& AIDS 2008; 19: 519-523.

5. Eriksson LE, Nordstrom G, Berglund T, Sandstrom E. The health-related quality of life in a Swedish sample of HIV-infected persons. Journal of Advanced Nursing 2000; 32(5): 1213-23.

6. Rüütel K, Pisarev H, Loit HM, Uuskula A. Factors influencing quality of life of people living with HIV in Estonia: a cross-sectional survey. Journal of the International AIDS Society 2009; 12:13.

7. Kovacevic SB,Vurusic T, Duvancic K, Macek M. Quality of Life of HIV Infected Persons in Croatia.Coll. Antropol. 2006; 30 (Suppl. 2): 79-84

8. CDC-Health related quality of life [Internet]. National Center for Chronic Disease Prevention and Health Promotion; [updated 2010 June 3; cited $2011 \mathrm{Feb}$ 17] Available from: http://www.cdc.gov/hrqol.

9. O'Connell K, Skevington S, Saxena S. WHOQOL HIV Group, Preliminary development of the World Health Organization's Quality of Life HIV instrument (WHOQOL-HIV): analysis of the pilot version. Soc Sci Med 2003; 57: 1259-75.
10. Basavaraj $\mathrm{KH}$, Navya MA, Rashmi R. Quality of life in HIV/AIDS. Indian J Sex Transm Dis 2010; 31(2):7580.

11. Mental Health: Evidence and Research, Department of Mental Health and Substance Dependence, World Health Organization. WHOQOL-HIV Instrument, Users Manual: Scoring and Coding for the WHOQOLHIV Instruments. Geneva: World Health Organization; 2002.

12. Skevington SM, O'connell KA. Measuring quality of life in HIV \& AIDS: a review of the recent literature. Psychology and Health 2003; 18 (3): 331350

13. Starace FL, Cafaro N, Abresci A, Chirianni C, Izzo P, Rucci G, Girolamo D. Quality of life assessment in HIV-positive persons: application and validation of the WHOQOL-HIV, Italian version. AIDS Care 2000; 14(2): 405-408.

14. Nirmal B, Divya KR, Dorairaj VS, Venkateswaran K Quality of life in HIV/AIDS patients: A cross-sectional study in south India. Indian $\mathbf{J}$ Sex Transm Dis 2008;29:15-7.

15. Santos EC, França I, Lopes F. Quality of life of people living with HIV/AIDS in São Paulo, Brazil. Rev Saúde Pública 2007;41(Supl. 2): 1-7.

16. Wig N, Lekshmi, R, Pal H, Ahuja V, Mittal CM, Agarwal S. The impact of HIV/AIDS on the quality of life: A cross sectional study in north India. Indian Journal of Medical Science 2006; 60(1): 3-12.

17. Nojomi M, Anbary K, Ranjbar M. Health-Related Quality of Life in Patients with HIV/AIDS Arch Iranian Med 2008; 11 (6): 608-12.

18. Molassiotis A, Callaghan P, Twinn SF, Lam SW. Correlates of quality of life in symptomatic HIV patients living in Hongkong. AIDS Care 2001;13(3):319-334.

19. Mrus JM, Williams PL, Tsevat J, Cohn SE, Wu AW. Gender differences in health-related quality of life in patients with HIV/AIDS. Qual Life Res 2005; 14:479_ 91.

20. Rai Y, Dutta T, Gulati AK. Quality of Life of HIV Infected People Across Different Stages of Infection. J Happiness Stud 2008;11: 61-69.

21. Mrus JM, Leonard AC, Yi MS, Sherman SN, Fultz SL, Justice AC, Tsevat J. Health-Related Quality of Life in Veterans and Nonveterans with HIV/AIDS" J Gen Intern Med; 2006; 21(S5):S39-S47.

22. Cohen C, Revicki DA, Nabulsi A, Sarocco PW, Jiang P. The Advanced HIV Disease Ritonavir Study Group: A randomized trial of the effect of ritonavir in maintaining quality of life in advanced HIV disease. AIDS 1998; 12: 1495-1502. 